Hanbury; but I must be mistaken in supposing there are not two Mr. Daniel Hanburys residing in Plough-court, Lombard. street, for in the Pharmacentical Journal for June last is a paper by a gentleman of that name, which was reprinted and circulated by himself, and therefore I supposed really contained an opinion not instantly to be recanted without notice, to the following effect: "After treating the powdered bean with cold alcohol, and farther exhausting the residue with similar alcohol at a boiling temperature, ...... the residue of the bean ...... was dried; and, with a view of ascertaining if it still contained a poisonous principle, some of it, mixed with bread and lard, was administered to a monse and rat. Neither animal would eat the mixture very readily. The mouse, after some hours, ate a pellet containing five grains of the residue, and died in the course of the next day. To the rat, which at intervals ate a much larger quintity, the residue also proved fatal in about forty hours. These experiments show that the bean had not been entirely deprived of its active properties."

I must ask the two Mr. Hanburys (if there be two) to recon cile two such opposite statements as the result of experiments made in the same laboratory; and if only one Mr. Hanbury, which of his assertions is to be regarded as the true one. I am, Sir, your faithful servant,

Leeds, Dec. 6th, 1863. THos. NUNNELEY, F.R.C.S.

\section{THE CASE OF}

\section{SYMM VERSUS FRASER AND ANDREWS.}

\section{To the Editor of THE LANCET.}

SrR, - I am glad to see that you have opened a subscription Sist for the defrayment of the expenses which Dis. Fraser and Andrews have been put to in defending themselves from what, as all admit, was a most groundiless charge, and I gladly enclose my mite.

Medical prosecutions are becoming alarmingly common; and I have little doubt that, if they are persevered in for any length of time, they will greatly cripple the usefulness of the profession. Self-preservation being the first law of nature, it will be to the interest of medical men to leave dangerous patients to take care of themselves; and ultimately the public, and not the profession, will suffer.

In reviewing the recent cases, it is impossible to divest oneself of the idea that lawyers are the chief supporters of these trials; for whenever the plaintiff and defendant are persons of means, there seems to be no difficulty experienced either in finding a solicitor to prepare or a barrister to support the case, no matter how evident it is that they are balancing the reputation of honourable men in the scales of injustice. Blacksheep there are, no doubt, amongst us; but it is not these that have been recently dragged into court. It therefore behores the profession to take into consideration the possibility of preventing a repetition of such trials as the last. Is personal liberty more dear to the British public than personal honour? Are the very means of subsistence of honourable men to be kept at the mercy of every moneyed dehauchee? For he it remembered that ruin may follow even a triumphant acquittal of the accused.

Harley-street, Dec. 1863. I am, Sir, yours \&c.

\section{POOR.LAW MEDICAL REFORM.}

\section{To the Editor of THE LANCET.}

SIR, - Some months have elapsed since I troubled you with any communication relative to the grievances of Poor-law medical officers and those of the poor entrusted to their care, and I fully intended to wait patiently until the meeting of the Select Committee on Paor-law Relief next session, when I hoped and still trust the subject will be considered by them; but the recent illness of my son, Dr. Griffin, of Southampton, who has lately become a Poor-law medical officer in consequence of his having entered into partnership with a gentleman (since dead) who held a Poor-law appointment-induces me to request the favour of your allowing me to lay before my professional brethren the heartless conduct of Poor-law guardians in their corporate capacity, not only in reference to the medical officer, but also to the ponr. In order that your readers may anderstand the circumstances, I will premise that my son, after attending 170 cases of scarlet fever, at length succumbed to that disease, and was, and still is, incapable of attending to his duties. As soon as he was able to hold a pen, he wrote a letter (see page 688) to the Board of Guardians, who, in reply, passed a resolution by a majority of two-" That if Dr. Griffin is dis- satisfied with the terms on which he holds his appointment of district medical officer, that he be requested to tender his resig. nation of the same." This resolution proves that unless Parliament interfere by some stringent regulations, the monstrous cruelty to the poor and their medical officers which now exists will still continue unredressed.

Weymouth, Dec. 4th, 1863. I am, Sir, yours \&c., Richard Griffin.

D U B I I N.

(EROM OUR OWN CORRESPONDENT.)

Two important steps have been recently taken by the Board of Trinity College with reference to medical degrees. The first is, that they have resolved to admit to examination for their licence in medicine, on payment of a fee of $£ 5$, all gentlemen who have passed an examination in Arts equivalent to their entrance examination and the first examination in the junior freshman year-the fee for which examination is fixed at $£ 15$; but for this latter fee they are entitled to three free courses of medical lectures, which, at $£ 33 s$. each, make a sum of $£ 99$. to be deducted from the $£ 20$. So that this University licence in Medicine will eventually cost but $£ 1011 s$. -cheap enough in all conscience; so cheap that, in my mind, hereafter to make it a formidable rival to the licence of our several Colleges of Physicians, the more so as, if its holder choose to complete his course in Arts, it will entitle him to take out the title of M.D., no further medical examination being requisite.

The second step taken by the University authorities is to question the right of our College of Physicians to insert in their licence the words "doctor of medicine." The College of Physicians had not originally attempted to grant degrees, the licences granted by their letters testimonial being the licentia medicince exercenda quam diu se bene gesserit. But in 1860 , for the first time, they conceived the design of granting degrees, and adopted the following form: "We grant licence to $\mathrm{A}$. $\mathrm{B}$. to practise in physic, and to certify that he is entitled to the degree and title of medical licentiate." They afterwards varied the form, adding to the letters testimonial the certificate that the candidate was thereby entitled to the title doctor of medicine and qualification of licentiate, which form the Board of Trinity College assert is by law confined, so far as Ireland is concerned. to themselves and the Senate of the Queen's University. They have therefore, with the view of having the matter legally decided, brought it into the Court of Chancery, where the question was entertained for the better part of two days, counsel eminent in the law having been retained on both sides; but the procesdings came to an abrupt termination in consequence of his Lordship declaring, "non nostrum inter vos tantas componere lites," inasmuch as he was Vice. Chancellor of the Queen's University, a body interested in the decision. The case has consequently been referred to the Master of the Rolls, whose decision, however, is open to appeal, when, in the ordinary course of events, it should be referred to the Court of A ppeal, the judges of which are, one the Vice-Chancellor of the University of Dublin, the other the Vice-Chancellor of the Queen's University. Under these circumstances, it is generally supposed that the ultimate decision will be left with one of the judges of our common law courts.

The first meeting for this session of our Pathological Society was held on the 28 th ult., the outgoing President, Mr. Hamilton, in the chair. The constitution of our Society is somewhat different from yours. Here no discussion is permitted : the menIber exhibits his specimen, making any remarks upon it which he sees fit, but no one else is allowed to make any observation or comment upon the subject. Almost every hospital physician and surgeon in this city is a member of the Society. Meetings are held weekly, and most valuable contributions to Anatomy and Pathology are brought forward on these occasions. Students of three years' standing are permitted to attend on members' tickets, which are in great demand; and if, by their conduct and attendance they are entitled to them, they receive at the termination of the session special certificates for such attendance. In addition, to encourage a laudable spirit of emulation, a gold medal is awarded at the termination of the session to the writer of the best essay on a subject selected and announced by the Council at the first meeting of the Society. For this the pupils of all our schools and hospitals eagerly compete, and on more than one occasion essays have been submitted for 